\title{
A multicentre trial of the aldose-reductase inhibitor, tolrestat, in patients with symptomatic diabetic neuropathy*
}

\author{
A.J.M. Boulton ${ }^{1}$, S. Levin ${ }^{2}$ and J. Comstock ${ }^{3}$ \\ ${ }^{1}$ Department of Medicine, Manchester Royal Infirmary, Manchester, UK \\ ${ }^{2}$ Wadsworth VA Medical Center, Los Angeles, California, USA \\ ${ }^{3}$ Houston VA Medical Center, Houston, Texas, USA
}

\begin{abstract}
Summary. The effects of the aldose-reductase inhibitor, tolrestat, on chronic symptomatic diabetic sensorimotor neuropathy were studied during a placebo-controlled, randomised, 52-week multicentre trial. Of the four tolrestat doses investigated, only the highest dose group, $200 \mathrm{mg}$ once daily, showed subjective and objective benefit over baseline and placebo, and further analyses are confined to this group $(n=112)$ and placebo $(n=107)$. Painful and paraesthetic symptoms were analysed separately: improvement in paraesthetic symptoms were seen at one year $(p=0.04)$, though painful symptoms improved on both placebo and active therapies. Significant improvement in both tibial and peroneal motor nerve conduction velocities were seen at 52 weeks. Tolrestat $200 \mathrm{mg}$ once daily was significantly better than
\end{abstract}

placebo in producing concordant improvements in both motor nerve conduction velocities and paraesthetic symptom scores at 24 weeks $(p=0.01), 42$ weeks $(p=0.01)$ and 52 weeks $(p=0.02)$. Long-term benefit [condordant improvement at 24 weeks maintained until 52 weeks] was seen in $28 \%$ of treated patients compared to $5 \%$ on placebo $(p=0.001)$. It is concluded that some sustained improvement in symptomatic diabetic neuropathy may be obtained following aldose-reductase inhibition with tolrestat $200 \mathrm{mg}$ once daily.

Key words: Diabetic neuropathy, aldose-reductase inhibitors, nerve conduction.
Peripheral neuropathy is one of the major complications of diabetes with a prevalence rate that approaches $20 \%$ even when strict clinical and electrophysiological criteria are applied [1]. There is increasing evidence to implicate both metabolic and vascular abnormalities in the aetiology of this condition [2-7]. Interest has increasingly been focussed on one metabolic consequence of hyperglycaemia in the nerve: increased activity of the enzyme aldose reductase which leads to tissue accumulation of sorbitol, in association with depletion of myo-inositol $[2,4]$. A considerable body of animal data now confirms a pivotal role for the polyol pathway in the aetiology of experimental diabetic neuropathy $[2,4,8]$. Treatment with an aldose-reductase inhibitor (ARI) or myo-inositol supplementation in diabetic animal models can improve motor conduction velocity [9]. Although early studies on the effects of ARIs on human diabetic neuropathy were encouraging $[10,11]$, not all reports demonstrated benefit $[12,13]$. However, many of these studies were hampered by their very short-term treatment period, the longest period being 6 months.

Tolrestat ( $\mathrm{N}$-[[5-trifluoromethyl)-6-methoxy-1-naphthalenyl]-thiomethoxyl]-N-methylglycine), is an aldosereductase inhibitor with a 10 -h half-life [14], allowing once-daily administration, which has a favourable safety

\footnotetext{
* Prepared by the authors for the North American tolrestat in neuropathy research group.
}

profile [15]. In order to investigate the potential of this novel drug in the treatment of chronic, sensorimotor neuropathy, we evaluated the efficacy and safety of tolrestat in a placebo-controlled, randomised, double-blind trial in 550 patients during a 52 -week period.

\section{Subjects and methods}

\section{Subjects}

Five hundred and fifty patients with either Type 1 (insulin-dependent) or Type 2 (non-insulin-dependent) diabetes of at least four months' duration were recruited in 19 centres. Inclusion criteria were: male or post-menopausal female patients; stable diabetes (judged clinically and by glycosylated haemoglobin and fasting plasma glucose results prior to entry); symptoms of stable or increasing severity caused by peripheral neuropathy; and abnormal motor or sensory nerve conduction results in at least three of six tested nerves.

Patients with other possible causes of polyneuropathy were excluded by clinical and laboratory investigations (hepatic or renal disease; any malignant disease; excessive alcohol intake; abnormal serum B12; abnormal serological tests for syphilis).

The groups were all comparable as to numbers of patients, duration of diabetes and neuropathy. During the study, patients continued on their usual diabetic therapy, including oral hypoglycaemic agents or insulin. No other treatment for peripheral neuropathy (eg., tricyclic drugs, phenytoin) was permitted, except for occasional, as needed, non-narcotic analgesic drugs.

Informed consent was obtained from all patients, and ethical committee approval was granted at every centre. 


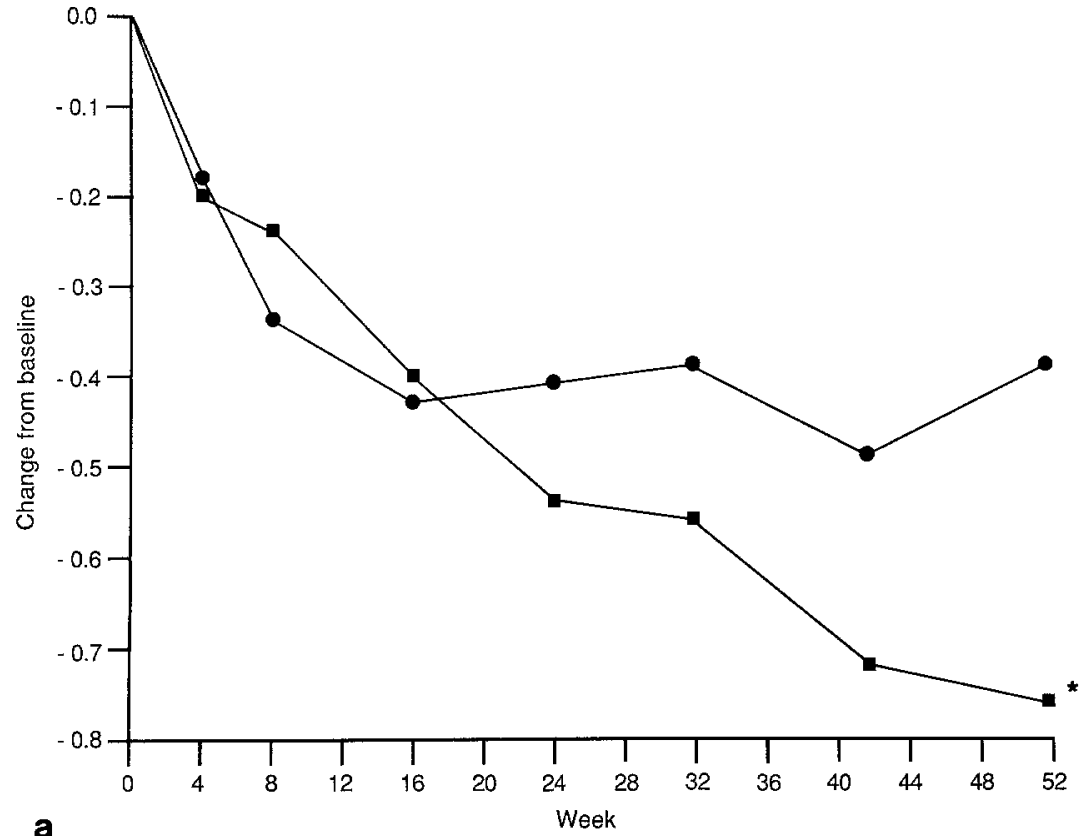

Fig. 1a, b. The effect of tolrestat $200 \mathrm{mg}$ once daily on the severity of the (a) paresthetic symptoms and (b) painful symptoms: least squares mean change from baseline. $\mathbf{0}$ = placebo; $\mathbf{\square}=$ tolrestat

$* p=0.04$ compared with placebo

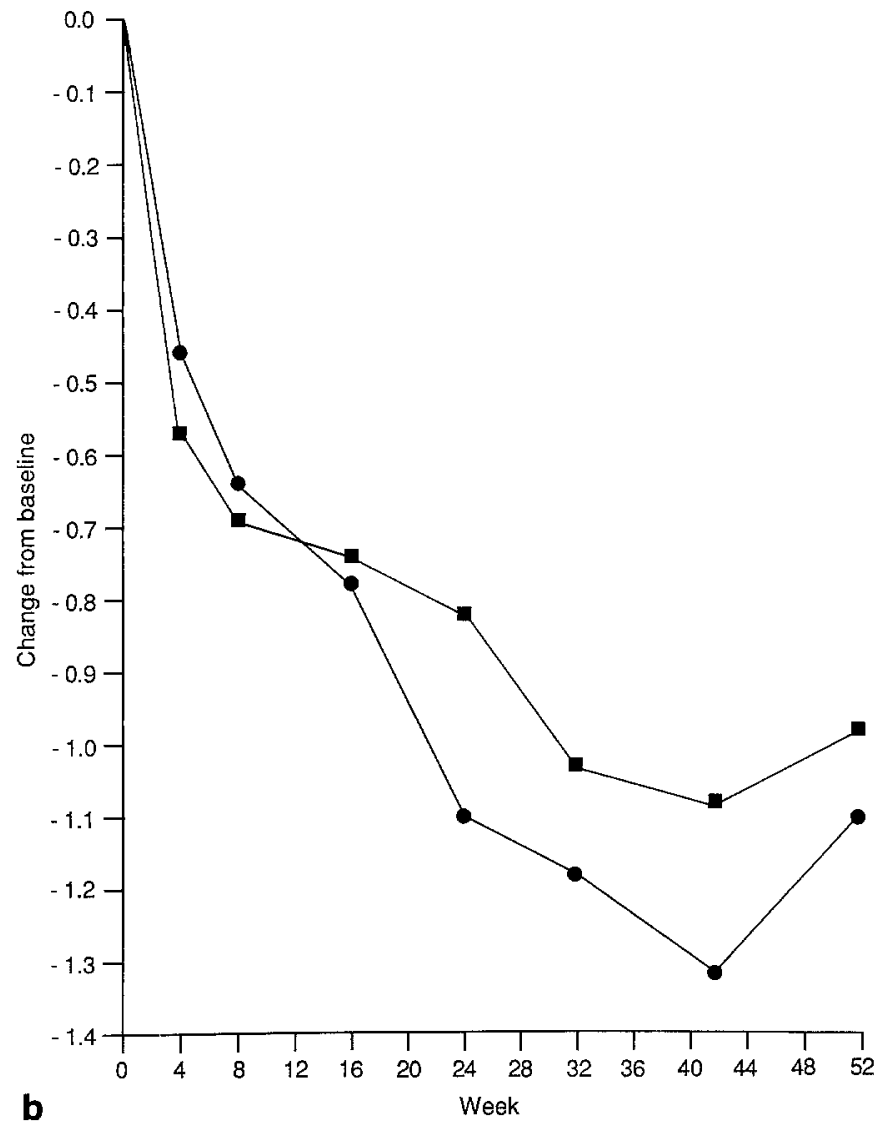

\section{Drug administration}

Patients were randomised to receive one of five treatments for up to 52 weeks: tolrestat 50,100 or $200 \mathrm{mg}$ once daily, tolrestat $100 \mathrm{mg}$ twice daily or placebo. Each patient received morning and evening doses taken $30 \mathrm{~min}$ before breakfast or dinner. In those patients receiving tolrestat once daily, the active drug was given in the morning. Patient compliance was assessed by counting returned tablets: no significant differences between groups were observed during the trial.
The study was conducted on an outpatient basis, with visits at weeks $2,4,8,12,16,20,24,32,42$ and 52 . The efficacy and safety assessments detailed below were repeated at some or all visits.

\section{Efficacy assessments}

Symptomaticassessments. The patients were asked to grade the present severity of the three most troublesome neuropathic symptoms of either pain or paraesthesiae on a 5 point scale: $0=$ absent, $1=$ mild, $2=$ moderate, $3=$ severe and $4=$ very severe. Symptoms were characterised as pain (eg., burning, deep aching, tenderness) or paraesthesiae (eg., pins and needles, asleep feeling) by the investigator at the time of assessment. These symptoms were assessed separately as most patients complained of both pain and paraesthesiae. Changes in symptom scores were assessed at weeks 4, 8, 16, 24, 32, 42 and 52.

Objective measurements. Changes in nerve function were assessed by nerve conduction velocity measurements. Four motor (peroneal, tibial, median, and ulnar) and two sensory nerves (median and sural) were assessed at baseline and after 8, 24,42 and 52 weeks of therapy. Surface electrodes were used with skin temperature maintained between $33^{\circ}$ and $35^{\circ} \mathrm{C}$, and averaging was applied as needed.

In order to account for baseline differences and differences between investigative sites in the range of normal nerve conduction values, the percentage change from baseline was determined and used for all statistical evaluations. In addition, the average percentage change in motor nerve conduction velocity (MCV) for each patient at a given visit was calculated in order to analyse the concordance between objective and subjective changes. An analysis was also performed on the number of motor nerves improved per patient out of a total of the four nerves that were tested.

Clinical response. In order to define a relationship between objective and subjective symptomatic improvements, patients were categorised as follows: responders showed improvement in both motor nerve conduction velocity and neuropathic symptom scores, failures showed deterioration or no change in both neuropathic indices, and all other patients were considered to be partial responders. This analysis was done at weeks 8,24, 42 and 52 using paraesthetic symptoms and painful symptoms. In addition to exploring the possible relationship between objective and subjective responses, this concordance analysis assesses the relevance of objective changes and can identify improvement or prevention of further deterioration. 
Table 1. The effect of tolrestat $200 \mathrm{mg}$ once daily on motor nerve conduction velocity (metres/second): least squares mean percentage change from baseline $\pm \operatorname{SEM}(n)$ [baseline $\mathrm{m} / \mathrm{s}$ ]

\begin{tabular}{|c|c|c|c|c|c|}
\hline \multirow[t]{2}{*}{ Motor nerve } & \multirow[t]{2}{*}{ Treatment group } & \multicolumn{4}{|l|}{ Week } \\
\hline & & 8 & 24 & 42 & 52 \\
\hline \multirow[t]{2}{*}{ Peroneal } & Placebo & $\begin{array}{l}-0.25 \pm 1.29(72) \\
{[35.49]}\end{array}$ & $\begin{array}{l}0.80 \pm 1.15(68) \\
{[35.73]}\end{array}$ & $\begin{array}{l}1.18 \pm 1.99(54) \\
{[35.63]}\end{array}$ & $\begin{array}{l}-3.23 \pm 2.32(45) \\
{[36.89]}\end{array}$ \\
\hline & Tolrestat & $\begin{array}{l}-0.14 \pm 1.14(77) \\
{[35.94]}\end{array}$ & $\begin{array}{l}1.89 \pm 1.15(66) \\
{[36.46]}\end{array}$ & $\begin{array}{l}3.09 \pm 1.77(55)^{\mathrm{a}} \\
{[36.70]}\end{array}$ & $\begin{array}{l}2.94 \pm 2.29(45)^{\mathrm{b}} \\
{[37.80]}\end{array}$ \\
\hline \multirow[t]{2}{*}{ Ulnar } & Placebo & $\begin{array}{l}-0.15 \pm 1.24(89) \\
{[47.33]}\end{array}$ & $\begin{array}{l}-0.55 \pm 0.99(85) \\
{[47.16]}\end{array}$ & $\begin{array}{l}3.93 \pm 1.62(71)^{\mathrm{c}} \\
{[46.87]}\end{array}$ & $\begin{array}{l}1.34 \pm 1.70(60) \\
{[47.48]}\end{array}$ \\
\hline & Tolrestat & $\begin{array}{l}1.55 \pm 1.17(92) \\
{[47.70]}\end{array}$ & $\begin{array}{l}2.31 \pm 0.96(84)^{\mathrm{d}, \mathrm{e}} \\
{[47.70]}\end{array}$ & $\begin{array}{l}3.47 \pm 1.55(72)^{\mathrm{i}} \\
{[47.23]}\end{array}$ & $\begin{array}{l}2.50 \pm 1.57(61) \\
{[47.07]}\end{array}$ \\
\hline \multirow[t]{2}{*}{ Tibial } & Placebo & $\begin{array}{l}0.81 \pm 1.58(75) \\
{[35.65]}\end{array}$ & $\begin{array}{l}2.38 \pm 1.55(71) \\
{[35.61]}\end{array}$ & $\begin{array}{l}3.54 \pm 2.14(59)^{\mathrm{g}} \\
{[35.48]}\end{array}$ & $\begin{array}{l}-0.53 \pm 2.25(52) \\
{[35.92]}\end{array}$ \\
\hline & Tolrestat & $\begin{array}{l}2.34 \pm 1.38(80)^{\mathrm{h}} \\
{[35.44]}\end{array}$ & $\begin{array}{l}3.47 \pm 1.50(71)^{\mathrm{i}} \\
{[35.88]}\end{array}$ & $\begin{array}{l}4.82 \pm 2.01(63)^{\mathrm{j}} \\
{[35.73]}\end{array}$ & $\begin{array}{l}5.43 \pm 2.07(53)^{k, 1} \\
{[36.08]}\end{array}$ \\
\hline
\end{tabular}

a $p=0.041$ compared with baseline; ${ }^{\mathrm{b}} p=0.030$ compared with placebo; ${ }^{c} p=0.008$ compared with baseline; ${ }^{\mathrm{d}} p=0.019$ compared with placebo; ${ }^{\mathrm{e}} p=0.008$ compared with baseline; ${ }^{\mathrm{f}} p=0.013$ compared with baseline; ${ }^{\mathrm{g}} p=0.050$ compared with baseline; ${ }^{\mathrm{h}} p=0.046$ compared with baseline; ${ }^{i} p=0.011$ compared with baseline; ${ }^{i} p=0.009$ compared with baseline; ${ }^{k} p=0.026$ compared with placebo; ${ }^{1} p=0.005$ compared with baseline; ${ }^{\mathrm{m}} p=0.001$ compared with baseline

Long-term clinical response. Patients with a long-term response were required to show a clinical response at the week 24 visit that continued at the week 42 and 52 visits. Similar criteria were used to define long-term failures and partial responders.

\section{Drug safety}

Safety parameters were assessed throughout the study and all patients were included in these analyses. In addition to subjective complaints and clinical examinations, the following laboratory investigations were performed at every visit: $\mathrm{Hb}$, full blood count, fasting blood glucose, $\mathrm{HbA}_{1}$, urea and electrolytes, liver function tests and urinalysis. Creatinine clearance was measured at baseline and thereafter at weeks $8,16,24,32,42$ and 52.

\section{Statistical analysis}

The parametric variables (such as nerve conduction velocity and symptom score) were subjected to a two-way analysis of variance. This model, which evaluates treatment, investigator, and treatment by investigator effects, was employed to test for significant changes from baseline within treatment groups and for significant differences between each tolrestat group and the placebo group in change from baseline. The tests involving efficacy variables were one-tailed. An investigator was required to contribute a minimum of one eligible patient to each treatment group at each visit in order to be included in the efficacy analysis for that visit. Changes from baseline in the parametric variables are expressed as least squares means. The least squares mean is generated by the analysis of variance model, and it adjusts for the effects of unequal sample sizes among the investigators.

Categorical analyses were performed on the clinical response using the Cochran-Mantel-Haenszel test and on the frequency of abnormal laboratory values and patient complaints using the ChiSquare test.

\section{Results}

Of the 550 patients who entered the trial, $80 \%$ were male and $45 \%$ were judged to have Type 1 (insulin-dependent) diabetes by clinical assessment. Mean age was 55 years, duration of diabetes 14.8 years and of symptomatic neuropathy 6.9 years. No significant differences were observed between any of these parameters or in glycaemic control at entry or after randomisation, for any of the therapeutic groups.

Significant improvements over both baseline values and placebo-treated patients were only seen in those treated with tolrestat $200 \mathrm{mg}$ once daily, and subsequent results refer only to this treatment group $(n=112)$ and placebo $(n=107)$.

\section{Symptomatic response}

The effects of tolrestat $200 \mathrm{mg}$ once daily on paraesthetic and painful symptoms are shown in Figures $1 \mathrm{a}$ and $b$, respectively. No benefit of the drug over placebo was seen for painful symptoms. In contrast, no further improvement in paraesthetic symptoms was seen with the placebo after 8 weeks, and a significant improvement in paraesthetic symptoms over placebo was seen at the end of the trial in tolrestat-treated patients $(p=0.04)$.

\section{Objective assessments}

The effects of tolrestat $200 \mathrm{mg}$ once daily on MCVs are summarised in Table 1. Significant improvements over baseline were seen in all nerves at one or more assessment visits, and improvement over placebo was seen in both 
Week 8

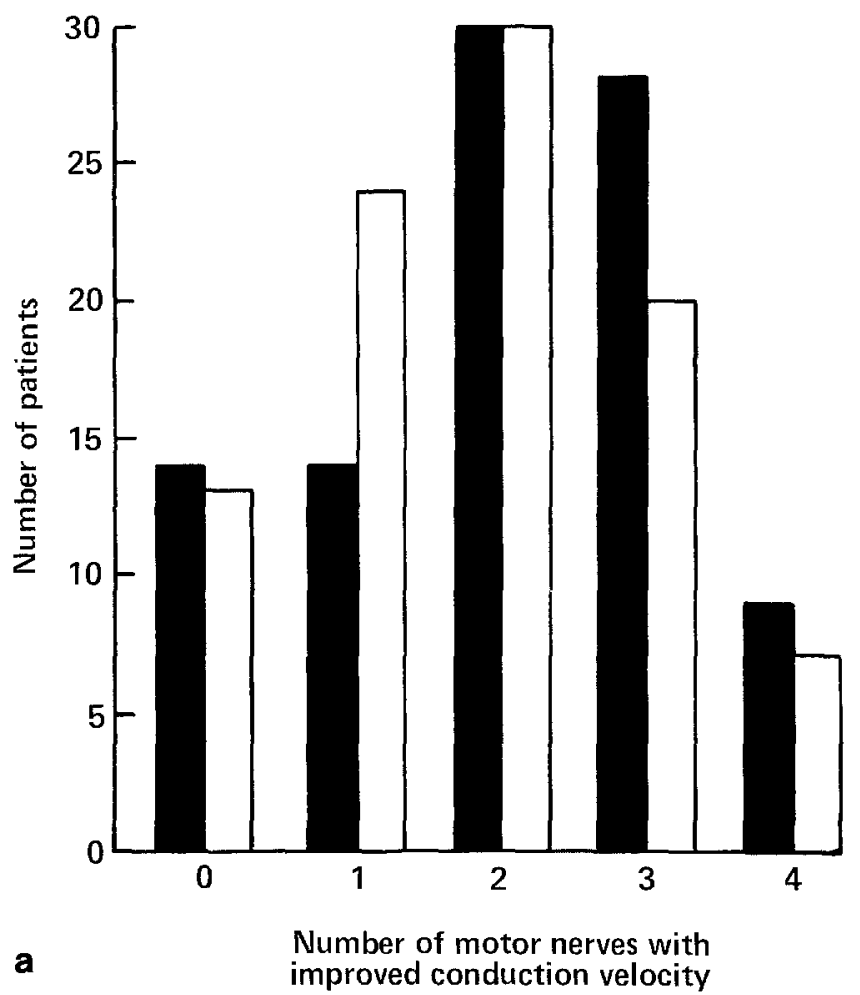

Week 42

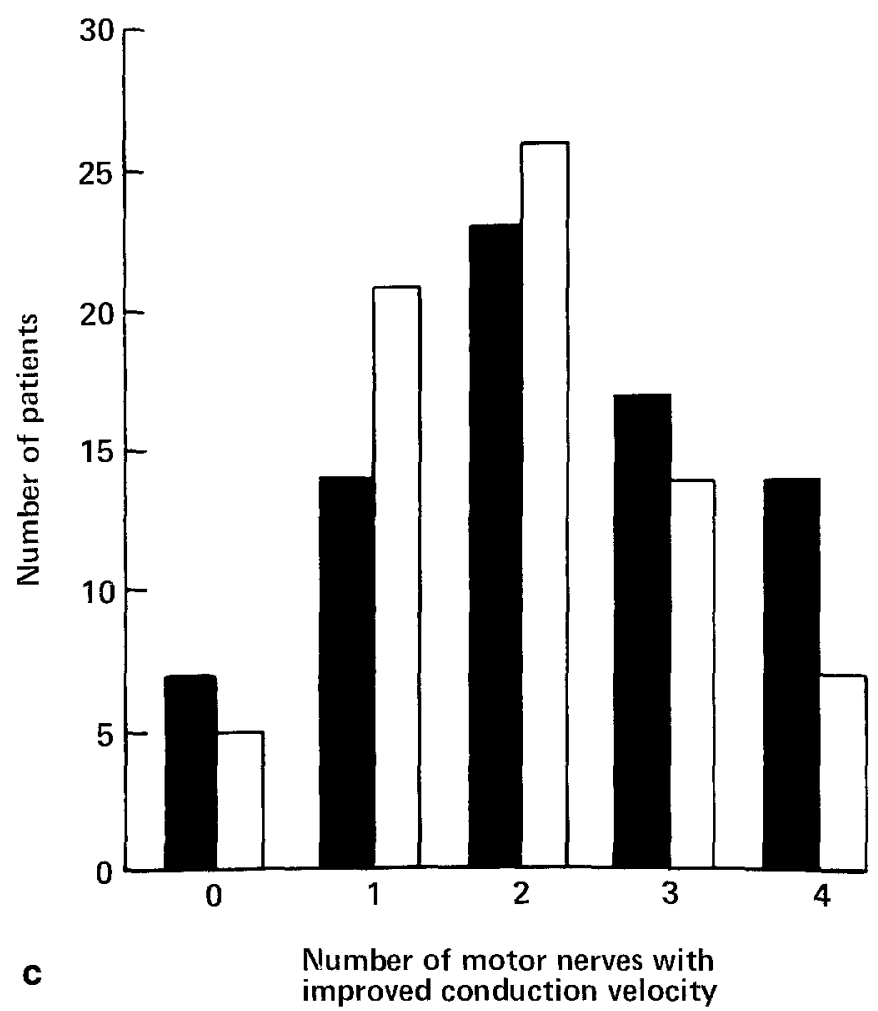

Fig. 2a-d. The effect of tolrestat $200 \mathrm{mg}$ once daily on the frequency distribution of motor nerves with improved conduction velocity compared with baseline (four nerves tested) at (a) week 8, (b) week 24, (c) week 42, and (d) week 52. Improvement defined as greater than $0 \mathrm{~m} / \mathrm{s}$. $=$ tolrestat; $\square=$ placebo. Total number of pa-
Week 24

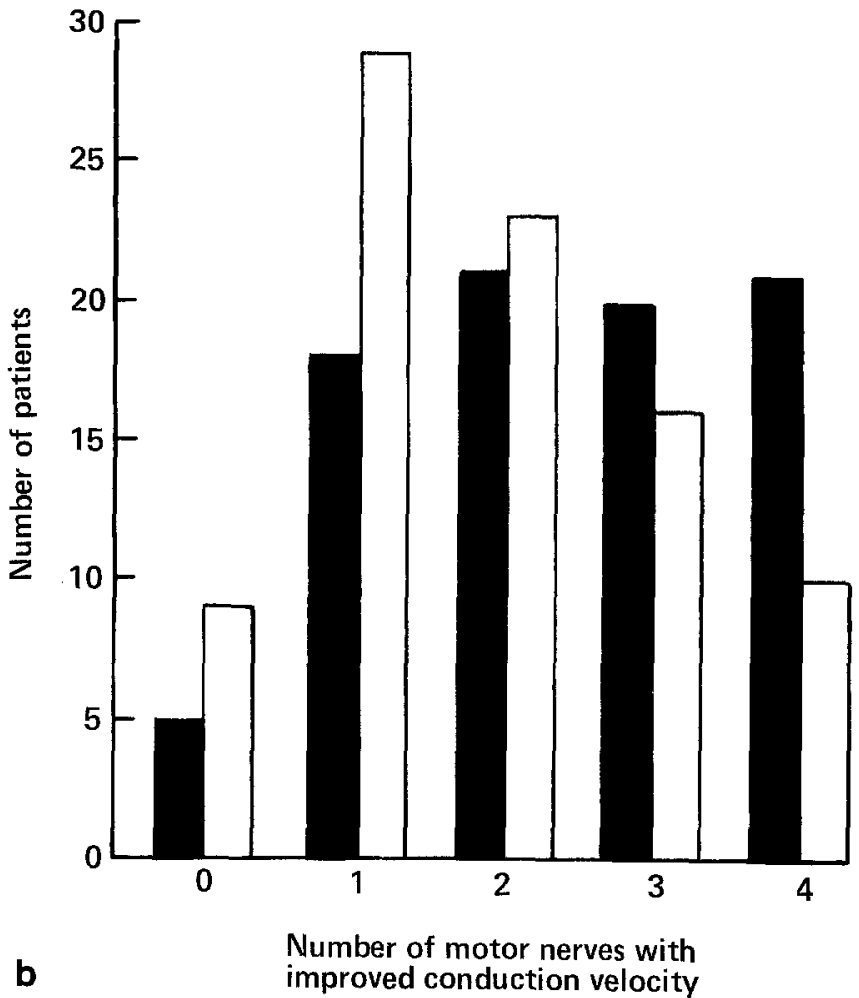

Week 52

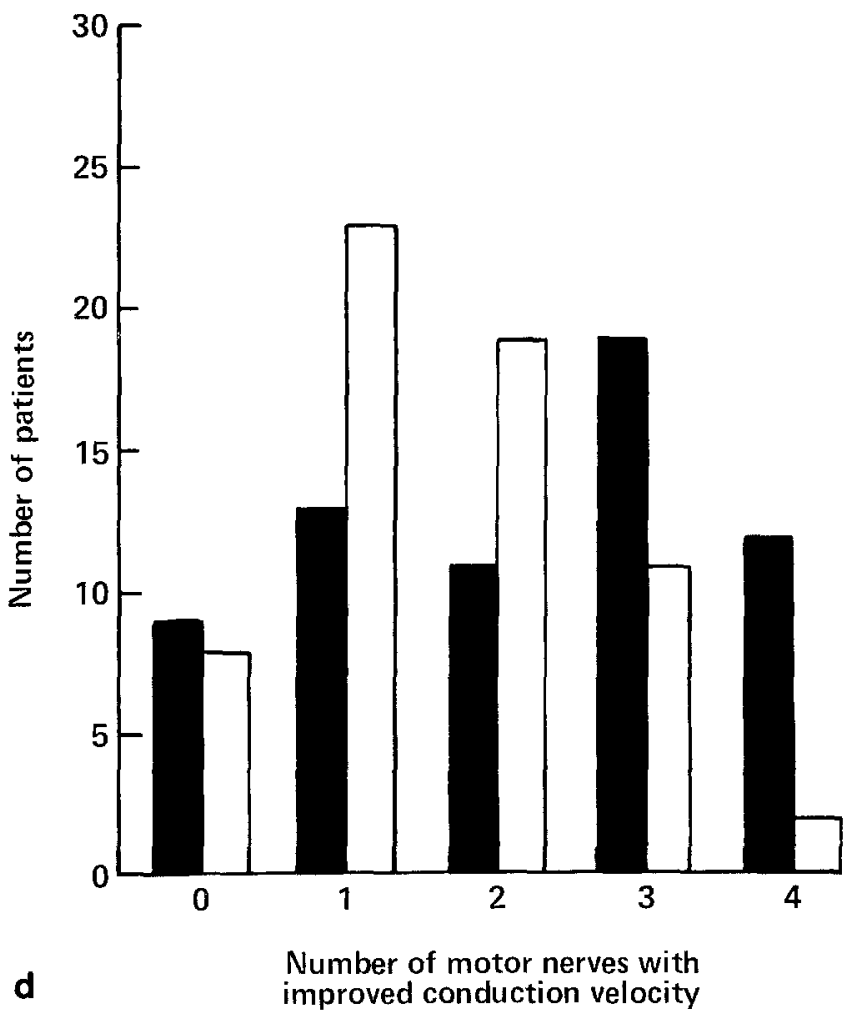

tients in tolrestat group at week $8,24,42$, and 52 was $95,85,75$, and 64 , respectively. Total number in placebo group was $94,87,73$, and 63 , respectively. Significance testing for tolrestat compared with placebo: week $8, p=0.11$; week $24, p=0.002$; week $42, p=0.08$; week $52, p=0.003$ 


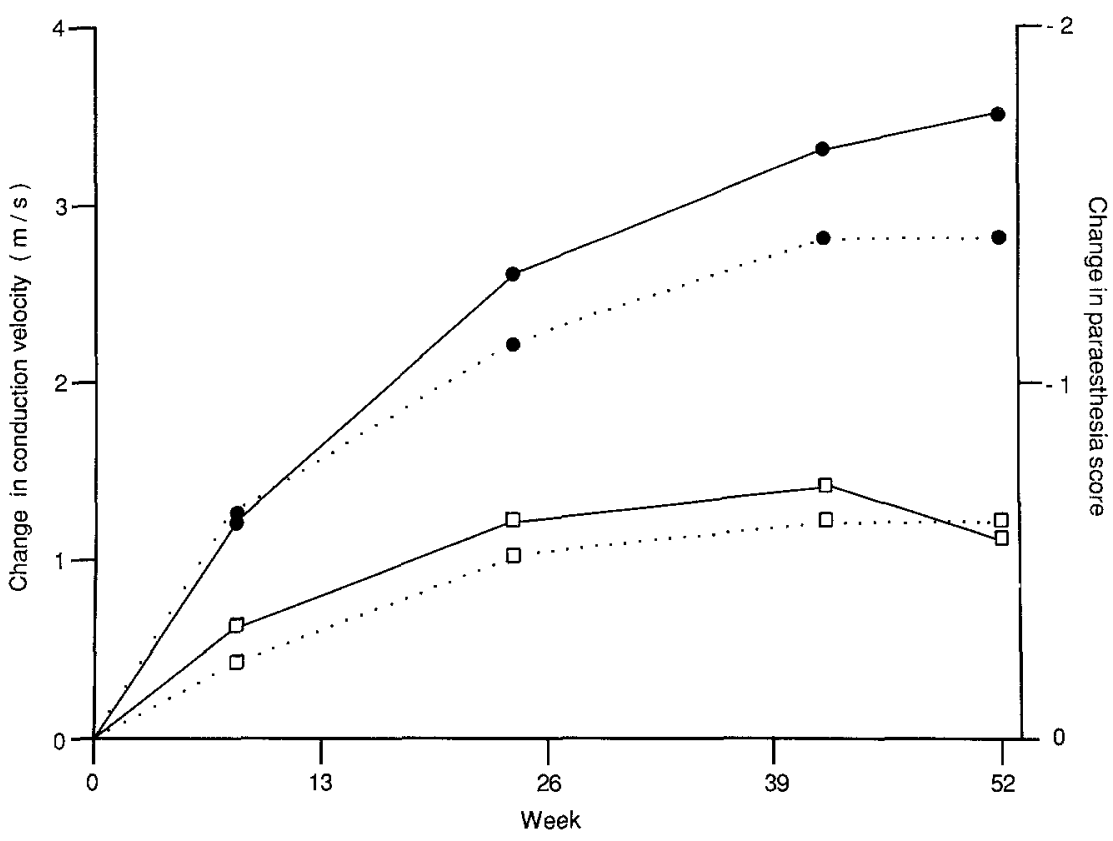

Fig.3. The effect of tolrestat $200 \mathrm{mg}$ once daily on the mean motor nerve conduction velocity and paraesthesia score. Long-term responders:

$\longrightarrow$ = motor nerve conduction velocity;

---- = paraesthesia score. All patients:

$\square-\square=$ motor nerve conduction velocity;

$\square---\square=$ paraesthesia score lower limb nerves at 52 weeks, and additionally in the ulnar nerve at 24 weeks. Highly significant changes in favour of tolrestat were seen when the number of motor nerves showing improvement was analysed and compared with placebo ( $p=0.002$ at 24 weeks; $p=0.003$ at 52 weeks; Fig. 2). No significant changes were observed in either of the sensory nerves tested.

\section{Clinical response}

The effect of tolrestat on the occurrence of concordant improvement in MCV and symptomatic severity was analysed, using paraesthesiae as the symptomatic index. Tolrestat treatment was associated with a significantly more favourable outcome at weeks 24,42 and 52 ( $p=0.012,0.103$ and 0.018 , respectively; Table 2). No benefit was demonstrated when pain was used as the symptomatic index.

\section{Long-term clinical response}

Since improvement in paraesthetic neuropathy may be a gradual response that becomes established after 24 weeks of treatment, a satisfactory long-term clinical response was defined as a continued improvement of both paraesthetic symptoms and MCV during the second 6 months of treatment, that is, at weeks 24,42 and 52 . Treatment failures showed no improvement in symptoms or MCV over the same time period, and all other subjects were considered long-term partial responders. Analysis of the frequency of patients in each category revealed a highly significant difference in favour of tolrestat compared with placebo (long-term clinical response $28 \%$ tolrestat vs $5 \%$ placebo; treatment failures $6 \%$ vs $19 \% ; p=0.001$ ).

The time course of the change in average nerve conduction velocity and paraesthesiae in all patients and in the subset of long-term clinical responders is shown in Figure 3.

\section{Safety}

Dizziness was the only drug-related patient complaint which occurred with a greater frequency in patients receiving tolrestat than in those receiving the placebo. In the case of the tolrestat $200 \mathrm{mg}$ once daily group, there was an $11 \%$ incidence compared with $3 \%$ on placebo $(p<0.05)$.

Table 2. The effect of tolrestat $200 \mathrm{mg}$ once daily on the occurrence of concordant improvements in functional (conduction velocity) and symptomatic (paresthesia severity) indices of nerve function

\begin{tabular}{|c|c|c|c|c|c|}
\hline \multirow[t]{2}{*}{ Outcome } & \multirow[t]{2}{*}{ Treatment } & \multicolumn{4}{|l|}{ Week } \\
\hline & & $\overline{8^{a}}$ & $24^{\mathrm{b}}$ & $42^{c}$ & $52^{\mathrm{d}}$ \\
\hline Response, $n,(\%)$ & $\begin{array}{l}\text { Placebo } \\
\text { Tolrestat }\end{array}$ & $\begin{array}{r}7(9.6) \\
15(19.2)\end{array}$ & $\begin{array}{l}15(21.7) \\
24(34.3)\end{array}$ & $\begin{array}{l}13(23.2) \\
24(39.3)\end{array}$ & $\begin{array}{l}13(26.5) \\
21(40.4)\end{array}$ \\
\hline $\begin{array}{l}\text { Partial } \\
\text { response, } n,(\%)\end{array}$ & $\begin{array}{l}\text { Placebo } \\
\text { Tolrestat }\end{array}$ & $\begin{array}{l}49(67.1) \\
39(50.0)\end{array}$ & $\begin{array}{l}34(49.3) \\
35(50.0)\end{array}$ & $\begin{array}{l}30(53.6) \\
29(47.5)\end{array}$ & $\begin{array}{l}20(40.8) \\
24(46.2)\end{array}$ \\
\hline Failure, $n,(\%)$ & $\begin{array}{l}\text { Placebo } \\
\text { Tolrestat }\end{array}$ & $\begin{array}{l}17(23.3) \\
24(30.8)\end{array}$ & $\begin{array}{l}20(29.0) \\
11(15.7)\end{array}$ & $\begin{array}{r}13(23.2) \\
8(13.1)\end{array}$ & $\begin{array}{r}16(32.7) \\
7(13.5)\end{array}$ \\
\hline
\end{tabular}

${ }^{\mathrm{a}} p=0.38 ;{ }^{\mathrm{b}} p=0.012 ;{ }^{\mathrm{c}} p=0.013 ;{ }^{\mathrm{d}} p=0.018$.

$p$ values refer to significance testing in the mean scores of tolrestat compared with placebo 
An evaluation of routine laboratory values was carried out. Compared with placebo, occasional increases in the least squares mean values of alanine aminotransferase (ALT) or aspartate aminotransferase (AST) were seen in patients taking tolrestat $100 \mathrm{mg}$ once daily, $200 \mathrm{mg}$ once daily, and $100 \mathrm{mg}$ twice daily. At no time did the least squares mean increase in ALT or AST exceed $22 \mathrm{U} / \mathrm{L}$. The number of dropouts from the study because of elevated hepatic enzymes (AST and ALT) was small: 2 patients on placebo, 2 on tolrestat $50 \mathrm{mg}$ once daily, 4 on $100 \mathrm{mg}$ once daily, 4 on $200 \mathrm{mg}$ once daily, and 5 on $100 \mathrm{mg}$ twice daily. In no instance was there evidence of severe hepatic dysfunction, and the changes in hepatic enzymes were reversible within 8-16 weeks of drug discontinuation. No changes in any other biochemical parameter were observed in any treatment group throughout the trial.

There were no significant changes in heart rate in any treatment group during the trial. However, there were minor but significant decreases $(p<0.05)$ from baseline of 3.8 to $6.6 \mathrm{~mm} \mathrm{Hg}$ in systolic blood pressure and 2.2 to $3.4 \mathrm{mmHg}$ in diastolic blood pressure in the tolrestat treatment groups. There were no changes from baseline in systolic or diastolic blood pressure in the placebo group.

\section{Discussion}

There is currently no therapy for chronic sensorimotor diabetic neuropathy that modifies biochemical abnormalities in peripheral nerves, with the possible exception of strict glycaemic control, which is notoriously difficult to maintain over a prolonged period of time [16]. Thus, the only effective treatment is for symptomatic relief, with imipramine having been demonstrated to be efficacious in double-blind trials [17]. However, such therapies are not known to influence the natural history of the condition, which is of gradual progression over years with persistence of symptoms and some reduction in MCVs [18, 19]. It is against this background that any trials of new therapies must be considered and compared.

In the present study, whereas no positive effects were seen in three treated groups, minor though consistent improvement in peripheral nerve function has been demonstrated following one year of treatment with tolrestat $200 \mathrm{mg}$ once daily in patients with long-standing sensorimotor diabetic neuropathy. Similar results have been reported using other aldose-reductase inhibitors for at least 6 months [13], as it is likely that any benefit will be gradual in onset, which might explain the disappointing results of some short-term trials [12]. This is further supported by data from the European multicentre trial of tolrestat [20], which has recently demonstrated results very similar to those in the present trial.

In assessing any therapy for chronic sensorimotor diabetic neuropathy it is important to recognize that structural damage has occurred, and that measurable recovery might take weeks or months to be detected. Sima and coworkers recently confirmed that improvement of the neuropathological lesions can occur following aldose-reductase inhibitor therapy for one year in patients with established neuropathy [21]. The present data are also con- sistent with the data on glycaemic control [22-25], which demonstrated that several weeks or months were required for significant improvements in nerve function to be seen. Moreover, the lack of significant changes in sensory nerve function is also similar to that seen in trials of strict glycaemic control, where little or no changes were observed [22-25]. In general, change in conduction is technically more difficult to detect in sensory nerves [26].

An important question raised by the present study and the literature is the magnitude of the change in motor nerve conduction velocity that can be expected in patients with long-standing neuropathy. The positive studies of aldose-reductase inhibitors and strict glycaemic control have generally shown MCV increases of $1-4 \mathrm{~m} / \mathrm{s}[10,13$, 22-25]. This is also consistent with the tolrestat results in this study of approximately $1-2 \mathrm{~m} / \mathrm{s}$. Both the modest response and its variability are to be expected in view of the severity of the disease, in that, while some patients may improve, others may not worsen and some may not respond at all. These problems of objective assessment are further compounded when evaluating symptoms. Although symptoms vary from day to day, may be difficult to recall or describe and are subject to a marked placebo response, their assessment is essential in clinical trials [16]. It is also possible that symptoms improve because of a progression rather than an improvement of the underlying pathology. It was in order to exclude this possibility that a concordance analysis was performed, which takes into account individual patient outcome and identifies patients with equivocal responses who tend to obscure overall group changes. The results of this analysis demonstrated the superior effects of tolrestat throughout the second half of the study, using paraesthesiae as the symptomatic index. The long-term responders demonstrated the greatest objective improvement, but no baseline clinical characteristic such as duration of diabetes or neuropathy could be identified that accurately predicted which patients might best respond to tolrestat therapy. The fact that a similar outcome was not observed using pain as the symptomatic index may reflect the recognized difficulties in the assessment of pain in a placebo controlled trial [27].

It is difficult to explain why significant changes were seen in patients treated with tolrestat $200 \mathrm{mg}$ once daily, whereas $100 \mathrm{mg}$ twice daily failed to provide any response. When the same dose is given once daily, higher initial levels are seen which should relate to drug effect [14]. As blood glucose flux is greater during the day, the fact that drug levels are greater during these hours on the $200 \mathrm{mg}$ once daily regimen might explain the observed difference in the results for these different dosages. A further inconsistency in the results from this trial is the fact that different nerves show significant improvement during the trial. However, similar findings are seen in most reports of the effect of strict glycaemic control on peripheral nerve function [22-25], and these are probably explained by the chronicity and natural history of the condition together with the recognised problems with repeated electrophysiologic measurements in multicentre studies.

The only significant side-effect during the study was dizziness which was experienced by $11 \%$ of patients receiving tolrestat $200 \mathrm{mg}$ once daily; however, this was not 
severe as no patient was dropped from the studies because of this complaint. There was no increased incidence of skin rash or a hypersensitivity reaction which has been observed with another aldose-reductase inhibitor [11, 13]. The only other problem encountered which is of clinical relevance in tolrestat treated patients has been an elevation of hepatic transaminases, which appeared to be drug related in approximately $2 \%$ of patients and which was reversible upon discontinuation of the drug [15].

In conclusion, the results of the present study suggest that a proportion of patients with established sensorimotor neuropathy benefited from tolrestat therapy, with approximately $30 \%$ demonstrating a clinical response. It is possible that aldose-reductase inhibition may become an important addition to glycaemic control in the treatment of neuropathy. However, it is unlikely that trials similar to this in patients with well-established neuropathy will provide useful additional information. There is now a need for long-term trials, either of prevention in diabetic patients without objective evidence of neuropathy, or of intervention in very early neuropathy.

Acknowledgements. This trial was supported by Wyeth-Ayerst Laboratories, New York, U.S. A.

\section{Investigators}

A.J.M.Boulton, J.S.Skyler (Miami, FL), C.Y.Bowers (New Orleans, LA), J. A. Colwell (Charleston, SC), J. P. Comstock (Houston, TX), J.Conomy (Cleveland, OH), H.Delcher (Atlanta, GA), J. M. Earll (Washington, DC), M. Feinglos (Durham, NC), Y. Harati (Houston, TX), D.G.Johnson (Tucson, AZ), R.M.Jordan (Little Rock, AK), S.Levin (Los Angeles, CA), J. Mersey (Baltimore, MD), R. M. Morrell (Allen Park, MD), L. Olansky (Oklahoma City, OK), B.Rao (Galveston, TX), M.S. Rendell (Tulsa, OK), J. V.Santiago (St. Louis, MO), L. F. Warrick (Madison, WI), and B. Gonen, W.Bochenek, J.F. Mullane, S. W. Ryder, D. G. Shand, J. Waksman, C.Perdomo (Wyeth-Ayerst Laboratories, NY)

\section{References}

1. Boulton AJM, Knight G, Drury J, Ward JD (1985) The prevalence of symptomatic diabetic neuropathy in an insulintreated population. Diabetes Care 8: 125-128

2. Greene DA, Lattimer SA, Sima AAF (1987) Sorbitol, phosphoinositides and sodium-potassium-ATPase in the pathogenesis of diabetic complications. N Engl J Med 316:599-606

3. Low PA (1987) Recent advances in the pathogenesis of diabetic neuropathy. Muscle Nerve 10: 121-128

4. Editorial (1989) Diabetic neuropathy. Lancet I: 1113-1114

5. Malik RA, Newrick PG, Sharma AK, Jennings A, Ah-See AK, Mayhew TM, Jakubowski J, Boulton AJM, Ward JD (1989) Microangiopathy in human diabetic neuropathy. Diabetologia 32: $92-102$

6. Gregersen G (1967) Diabetic neuropathy: influence of age, sex, metabolic control and duration of diabetes on motor conduction velocity. Neurology 17:972-980

7. Pirart J (1978) Diabetes and its degenerative complications: a prospective study of 4,400 patients observed between 1947 and 1973. Diabetes Care 1: 168-188 and 252-265

8. Greene DA, Chakrabarti S, Lattimer SA, Sima AAF (1987) Role of sorbitol accumulation and myo-inositol depletion in para-nodal swelling of large myelinated fibres in the insulin-deficient spontaneously diabetic bio-breeding rat. J Clin Invest 79 : 1479-1485

9. Mayer JH, Tomlinson DR (1983) Prevention of defects of axonal transport and nerve conduction velocity by oral administration of myoinositol or an aldose-reductase inhibitor. Diabetologia 25: 433-438

10. Judzewitsch RG, Jaspan JB, Polonsky KS, Weinberg CR, Halter JB, Halar E, Pfeifer MA, Vukadinovic C, Bernstein L, Schneider M, Liang KY, Gabbay KH, Rubenstein AH, Porte D (1983) Aldose-reductase inhibition improves nerve conduction velocity in diabetic patients. N Engl J Med 308:119-125

11. Young RJ, Ewing DJ, Clarke BF (1983) A controlled trial of sorbinil, an aldose-reductase inhibitor, in chronic painful diabetic neuropathy. Diabetes 32: 938-942

12. Lewin IG, O'Brien IAD, Morgan MH, Corrall RJM (1984) Clinical and neurophysiological studies with the aldose-reductase inhibitor, Sorbinil, in symptomatic diabetic neuropathy. Diabetologia 26: $445-448$

13. Fagius J, Brattberg A, Jameson S, Berne C (1985) Limited benefit of treatment of diabetic polyneuropathy with an aldosereductase inhibitor: a 24 week controlled trial. Diabetologia 28 : 323-329

14. Hicks DR, Kraml M, Cayen MN, Dubuc J, Ryder S, Dvornick D (1984) Tolrestat kinetics. Clin Pharmacol Ther 36: 493-499

15. Ryder S, Sarokhan B, Shand DG, Mullane JF (1987) Human safety profile of tolrestat: an aldose-reductase inhibitor. Drug Develop Res 11: 131-143

16. Boulton AJM, Ward JD (1986) Diabetic neuropathies and pain. Clin Endocrinol Metab 15: 917-931

17. Young RJ, Clarke BF (1985) Pain relief in diabetic neuropathy: the effectiveness of imipramine and related drugs. Diabetic Med $2: 362-366$

18. Bischoff A (1980) The natural course of diabetic neuropathy: a follow-up. Horm Metabl Res 9 [Suppl]: 98-100

19. Boulton AJM, Armstrong WD, Scarpello JHB, Ward JD (1983) The natural history of painful diabetic neuropathy: a four year study. Post Med J 59: 556-559

20. Boulton AJM, Atiea J, de Leeuw IH, Lemkes H, MacLeod AF, MacRury S, Scarpello JHB, Somers G, Tattersall RB, van der Veen EA (1989) The efficacy and safety of the aldose-reductase inhibitor tolrestat in the treatment of chronic sensorimotor diabetic neuropathy. Diabetologia 32: 469A

21. Sima AAF, Bril V, Nathaniel V, McEwan AJ, Brown MB, Lattimer SA, Greene DA (1988) Regeneration and repair of myelinated fibres in sural nerve biopsy specimens from patients with diabetic neuropathy treated with sorbinil. N Engl J Med 319: 548-555

22. Pietri A, Ehle AL, Raskin P (1980) Changes in nerve conduction velocity after six weeks of glucoregulation with portable insulin infusion pumps. Diabetes 29: 668-671

23. Boulton AJM, Drury J, Clarke BF, Ward JD (1982) Continuous subcutaneous insulin infusion in the management of painful diabetic neuropathy. Diabetes Care 5: 386-390

24. Graf RJ, Halter JB, Pfeifer MA, Halar E, Brozovich F, Porte D (1981) Glycaemic control and nerve conduction abnormalities in non-insulin-dependent diabetic subjects. Ann Intern Med 94: 307-311

25. Fedele D, Negrin P, Cardone C, Bellavere F, Ferri M, Briani G, Nosadini R, Crepaldi G (1984) Influence of continuous subcutaneous insulin infusion (CSII) treatment on diabetic somatic and autonomic neuropathy. J Endocrinol Invest 7: 623-628

26. Daube JR (1986) Nerve conduction studies. In: Aminoff MJ (ed) Electrodiagnosis in clinical neurology, 2nd edn. Churchill Livingstone, New York, pp 265-306

27. Kornetsky C (1976) Pharmacology: drugs affecting behavior. John Wiley and Sons, New York, pp $22-44$

Received: 23 October 1989

and in revised form: 15 February 1990

Dr. A.J.M. Boulton

Department of Medicine

Manchester Royal Infirmary

Oxford Road

Manchester M13 9WL, UK 